\title{
REVISITING THE NUCLEOPHILICITY CONCEPT IN A COMPREHENSIVE BIOMASS VALORIZATION EXPERIMENT: FROM PAPAYA SEEDS TO THIOUREA MOTIFS
}

\author{
Raquel V. dos Santos ${ }^{a}$, Gil M. Viana ${ }^{b}$, Anderson Felipe S. Moreira ${ }^{c}$, Vitor S. Nóbrega ${ }^{c}$, Vitor A. S. da Silva ${ }^{c}$, Luiz Fernando \\ B. Malta ${ }^{\mathrm{c}, *, \text {, }}$, Lucia C. S. Aguiar ${ }^{\mathrm{c}}$ and Jaqueline D. Senra ${ }^{\mathrm{a}}$ \\ anstituto de Química, Universidade do Estado do Rio de Janeiro, 20550-900 Rio de Janeiro - RJ, Brasil \\ ${ }^{b}$ Faculdade de Fármacia, Universidade Federal do Rio de Janeiro, 21941-614 Rio de Janeiro - RJ, Brasil \\ 'Instituto de Química, Universidade Federal do Rio de Janeiro, 21941-903 Rio de Janeiro - RJ, Brasil
}

Recebido em 02/02/2019; aceito em 12/06/2019; publicado na web em 07/08/2019

\begin{abstract}
The recovery of waste materials with potential for synthetic transformations is a major field in science. However, just few experiments have been devoted to undergraduate students by exploring some consistent subjects in light of simple, natural resources. Nucleophilicity is a central subject in chemistry and there are significant synthetic models to exploit it in contrast to basicity. Here we present a laboratory experiment that utilizes hands-on research to be implemented in an organic chemistry lab by using benzyl isothiocyanate (BITC) from papaya seeds as raw material for the preparation of thioureas in a fast and visually indicative experiment. Subjects such as green chemistry, extraction methods, nucleophilicity, chromatography and NMR spectroscopy can be emphasized in order to implement a project-based approach. This experiment shows flexibility concerning the procedures and the use of biomass raw materials towards the reinforcement of a research-like experience and critical-thinking skills.
\end{abstract}

Keywords: Green Chemistry; hands-on learning; third-year undergraduate students; Organic Chemistry.

\section{INTRODUCTION}

Advances in conceptual aspects related to fundamental topics in the undergraduate curricula constitute a valuable opportunity to improve chemistry education and encourage the development of chemical research skills in the students. To keep aligned with current trends in the undergraduate education, it is desired to consider the demands of the chemical education. ${ }^{1-3}$ In the last decades, changes in the conception of fossil fuel reservoirs have stimulated the exploitation of the sustainable chemistry principles as a promising possibility for the production of chemicals. ${ }^{4-8}$ In fact, there is a growing emphasis on the development of environmentally friendly and sustainable methods for the conversion of biomass-derived resources. Further transformation of raw materials in high-value aggregated products such as polymers, surfactants and specialty chemicals has promoted benefits to academic researches and industry as well as stimulated the incorporation of some purposes to science education alike. ${ }^{9}$ Since biomass relates to a wide complexity of compounds found in nature, it can inspire different advanced organic chemistry lab courses with focus on synthetic methodologies.

Papaya (Carica papaya) seeds represent an abundant, secure and stable waste material from papaya processing ${ }^{10}$ which contain benzyl glucosinolate (BG), the major one present. ${ }^{11}$ Glucosinolates are metabolized to yield isothiocyanates by the action of enzymes commonly called myrosinases, ${ }^{12-15}$ that are brought into contact with their substrate(s) upon damage to seeds in which they are found (Scheme 1). Many isothiocyanates occur naturally in plants consumed by humans (e.g., cruciferous vegetables) and are well recognized to have protective effects. ${ }^{16-19}$

In case of papaya, the benzyl isothiocyanate (BITC) formed from this enzymatic mechanism, can be precursor of important organic functional groups by direct nucleophilic addition (Scheme 2).

Thioureas are one of the most valuable products derived from isothiocyanates since the thioureido moiety is mostly involved into the design of biologically active compounds (Scheme 3) and supramolecular systems. ${ }^{20-30}$ In the academic field, thioureas are usually involved in the qualitative analysis of organic compounds. For instance, since amines have a remarkable importance as nucleophiles and/or bases in organic chemistry, advantage can be taken of the fact that some of them are converted into solid, sharpmelting substituted thioureas. In this case, by allowing them to react with an appropriate isothiocyanate, valuable information is obtained about the ability of amines to attack unsaturated electrophilic sites. However, simple experiments involving the relationships between

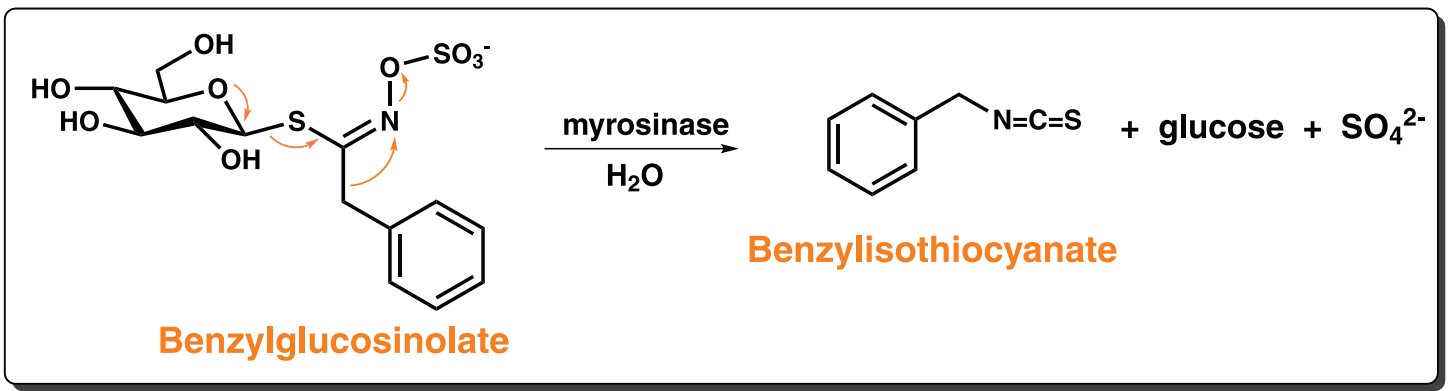

Scheme 1. Rearrangement of the glucosinolate promoted by myrosinase

*e-mail: lfbmalta@iq.ufrj.br 


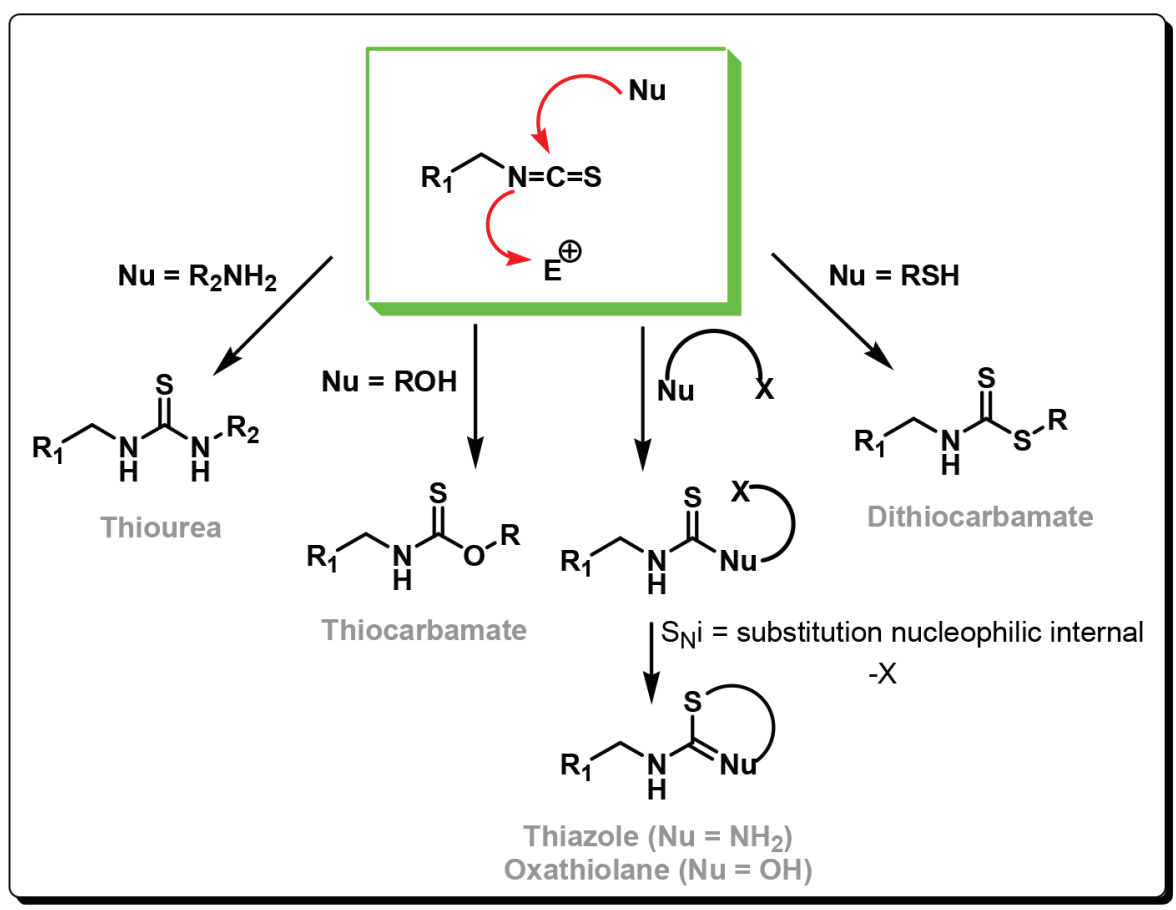

Scheme 2. General reactivity of isothiocyanates

their nucleophilicities and Lewis basicities $\left(\mathrm{pk}_{\mathrm{b}}\right)$ towards carbon centers have been poorly explored.

Double-bond nucleophilic addition reactions are among some of the first reactions covered in an introductory organic chemistry course. However, in the undergraduation context, we have observed that, in general, students have mastered the requisite synthetic techniques and theory but are less challenged to establish appropriate correlation between theory as well as the use of raw materials in organic synthesis.

An aid to the science demonstrations, most everyday samples provide a tool for the connection between natural products and chemical science. At home, papaya seeds are considered a waste but they can get a new status for the teaching laboratory, providing an introduction to natural product techniques while simultaneously demonstrating the formation of thioureas from nucleophilic amines. Previous work from our group ${ }^{31}$ has described the reaction between natural BITC and aryl/alkyl amines envisaging the synthesis of structurally diverse $N$-benzyl thioureas (Scheme 4).

Based on the availability and low price, amines with alkyl/ aryl chains were evaluated. There is a number of green chemistry experiments with focus in biomass extraction or its exploitation.
In order to provide an integrated learning experience ${ }^{32}$ for the students we propose an experiment that enables some advantages, such as: i) fast reaction time (approximately 10 seconds) at room temperature; ii) high-yields; and iii) facile product characterization (thin-layer chromatography, well-defined spots); iv) the preparation of valuable compounds (biologically active $N, N$-dialkyl/aryl thioureas) in a simple lab experiment. The demonstration offers a simple response based on visual inspection that we believe is pedagogically relevant to discussion of nucleophilicities since precipitation can occur immediately after the addition of some amines. Indeed, the inclusion of chromatographic techniques (e.g. HPLC) as well as physical methods of characterization (e.g. ${ }^{1} \mathrm{H}$ NMR) can enrich the approach.

\section{EXPERIMENTAL SECTION}

The laboratory experiment described here was idealized to run in two periods of $4 \mathrm{~h}$ (totalizing $8 \mathrm{~h}$ ) and was adapted from Aguiar and co-workers ${ }^{31}$ within the constraints of the laboratory setting. Full details can be found in the Supplementary Material.

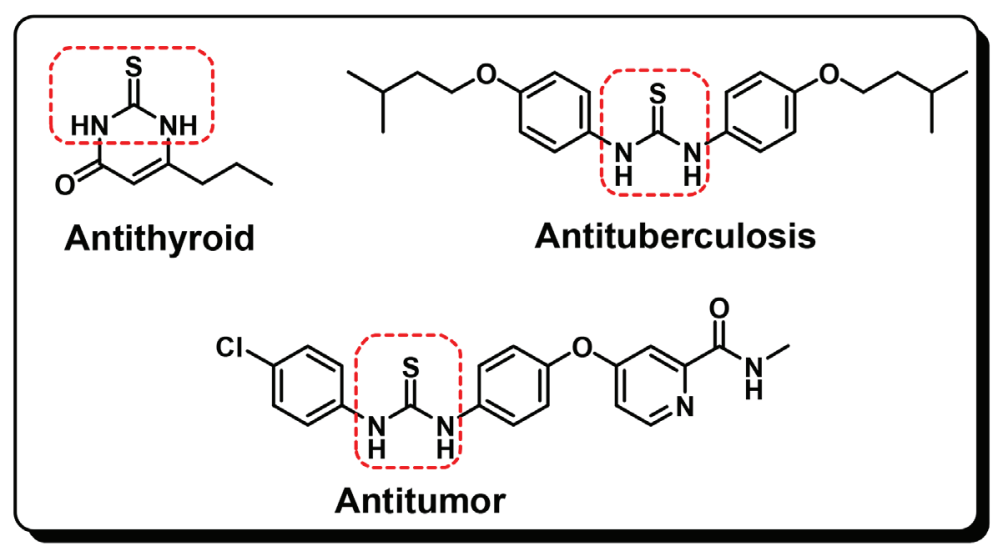



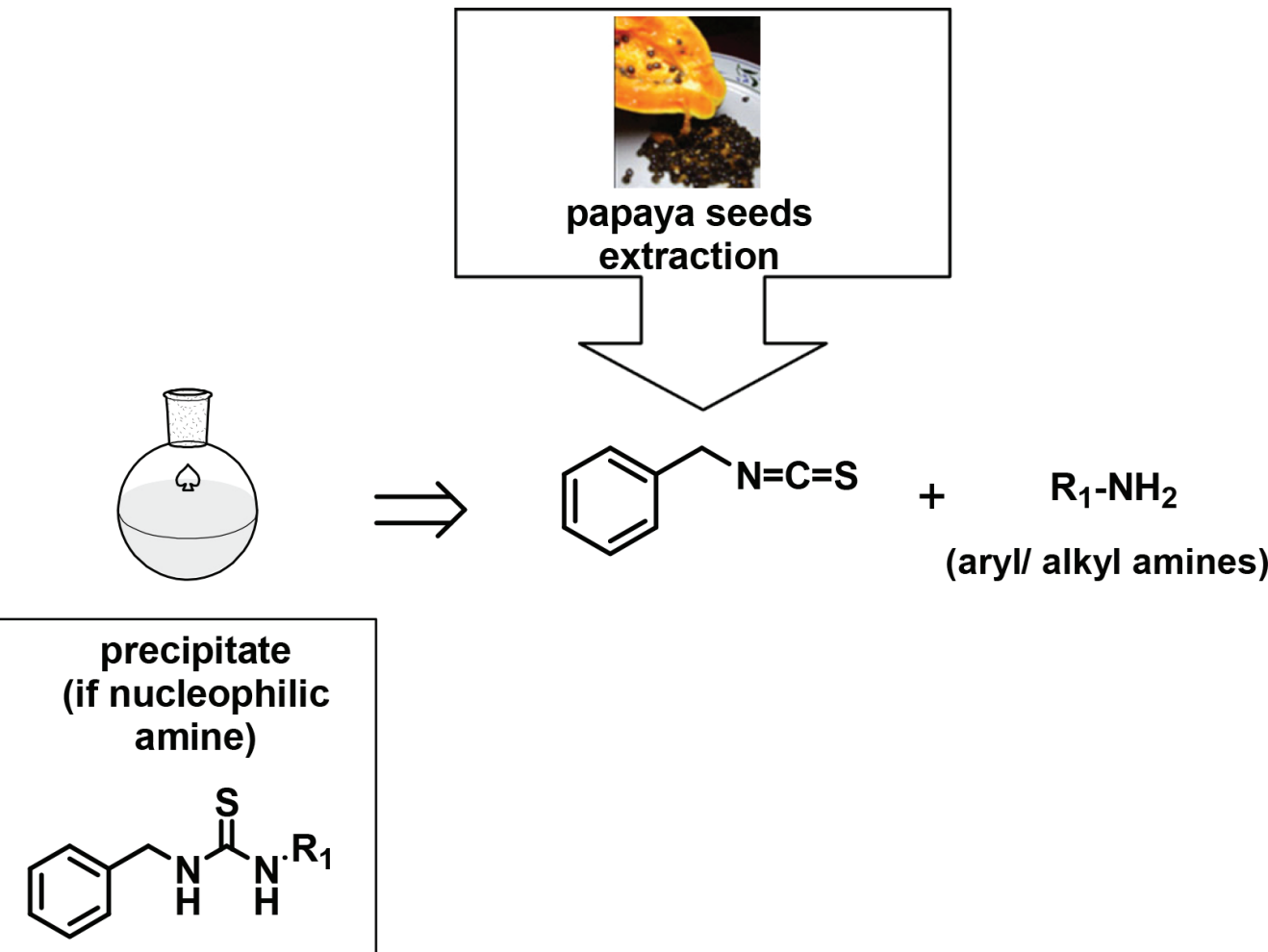

Scheme 4. Retrosynthetic analysis of the formation of thioureas from natural BITC

\section{Prelab and Postlab activities}

The experiment was successfully applied to more advanced students (3-year undergraduate students) divided in 3 groups. Aiming for a successful experiment, we considered important that the students would be familiar with the basic theory of characterization of organic compounds ( ${ }^{1} \mathrm{H}$ NMR and chromatography) and aspects related to basicity and nucleophilicity. Before and after the experiment, students were evaluated in the form of exercises. The pedagogical material is provided in the Supplementary Material.

\section{Procedures}

Experiment 1: Extraction of BITC from papaya seeds

The initial experiment consisted on the careful extraction of BITC from the wasted papaya seeds (See details in Supplementary Material). The methodologies employed here were the hydrodistillation and the continuous extraction mode (Soxhlet) as a way to compare the efficiency of both ones (Scheme 5). To each group was given approximately $140 \mathrm{~g}$ material (cold fresh seeds) obtained from 4 fruits.
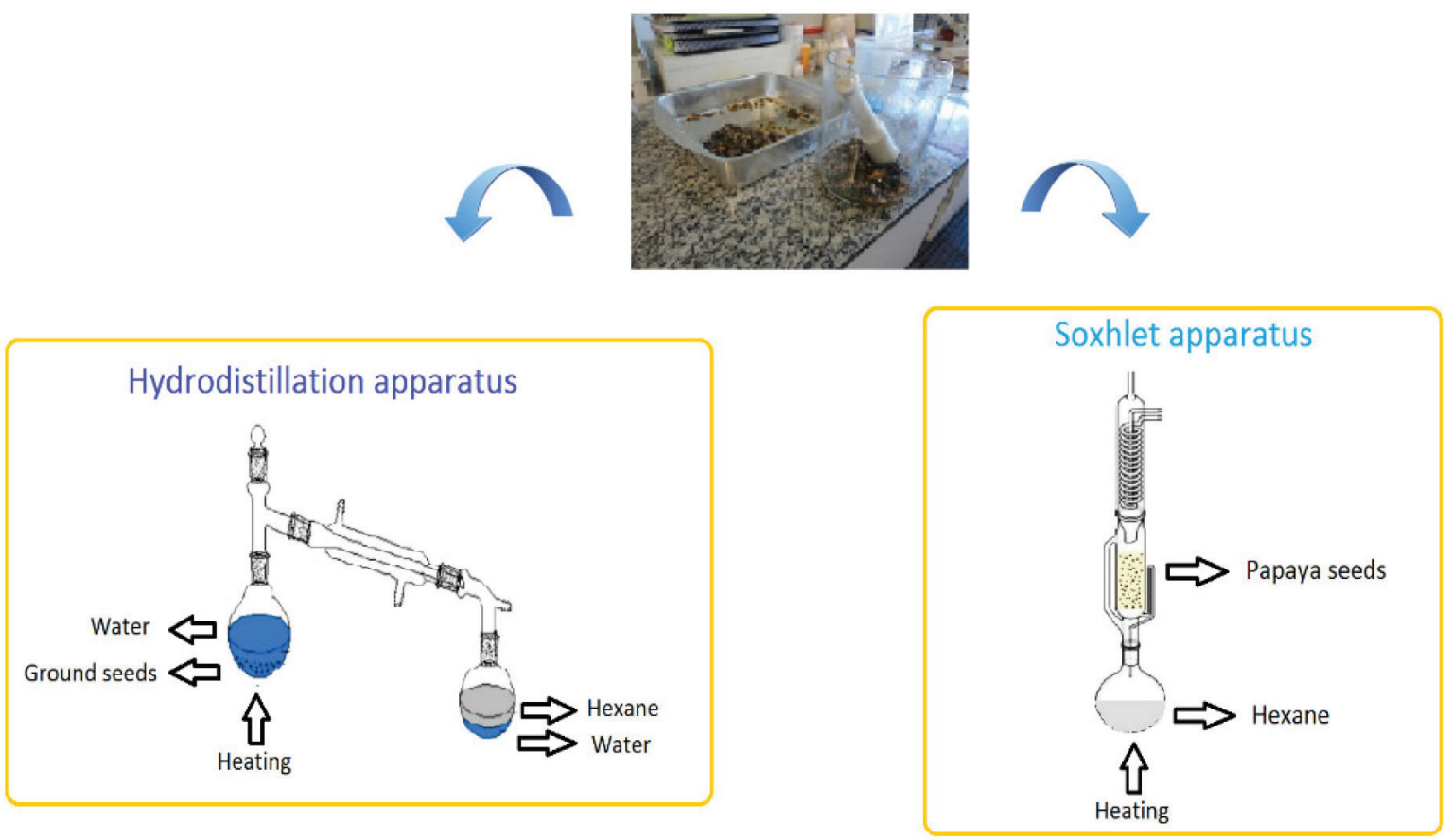

Scheme 5. BITC extraction from papaya seeds 
In the hydrodistillation strategy, the papaya seeds were ground in a mortar and pestle during some minutes and then the material was added to a 1L-round flask containing approximately $450 \mathrm{~mL}$ of distilled water. Then, a typical distillation apparatus was connected to the flask and the heating was conducted in a heating mantle for $3 \mathrm{~h}$. The distillated was collected in a flask containing about $60 \mathrm{~mL}$ of hexane. It was possible to identify a whitening emulsion from the vaporization/ condensation process indicating the drag of BITC. Indeed, some characteristic smell of BITC was noted by some students during the experiment..$^{33}$

Alternatively, in the continuous extraction (Soxhlet) mode, we used a thimble containing the ground material (approximately $200 \mathrm{~g}$ ) which was submitted to the continuous process of vaporization/ condensation of the solvent for $3 \mathrm{~h}$ or more. Since $n$-hexane and $n$-pentane are cheap non-chlorinated organic solvents and allows for a good miscibility of BITC we decided to use them $(\mathrm{v}=250 \mathrm{~mL})$ for the experiments.

Both apparatuses are represented in Scheme 5. The extracts were quantified by HPLC by using a calibration curve. For the ${ }^{1} \mathrm{H}$ NMR analyses, a small volume of the extracts (approximately $5 \mathrm{~mL}$ ) was evaporated under reduced pressure and dissolved in $\mathrm{CDCl}_{3}$ by using standard $5 \mathrm{~mm}$ NMR tubes.

Experiment 2: Exploiting the reactivity of different nucleophiles towards BITC

$$
\underset{n \text {-hexane, r.t. }}{\mathrm{NNH}_{2}}
$$

As an experiment for the introduction of the reactivity, different amines were used towards BITC (Scheme 6). Since the hexane solution of BITC from the steam distillation contains the pure material, we collected approximately $10 \mathrm{~mL}$ to start the reactivity tests. In most cases, the addition of about $0.1 \mathrm{~mL}$ of amines or alcohols to the BITC solution led to the formation of white precipitates immediately at room temperature.

\section{Hazards}

In general, the purposed experiments offer low general risks. Benzyl isothiocyanates have low toxicity but inhalation and skin contact should be avoided. However, alkyl and aryl amines are skin irritants, corrosive, and irritating to the mucous membranes. Besides the use of personal protective equipment (PPE), students should avoid inhalation and skin contact along with wear eye protection and gloves.

\section{RESULTS AND DISCUSSION}

Each group had two periods of $4 \mathrm{~h}$, totalizing $8 \mathrm{~h}$ for the experiment. In the first experiment, the comparison of the efficiency involving the extraction methodologies represented an excellent opportunity to address specific questions about the distillation theory along with the physical processes involved with the extraction operation. In the steam distillation principle, the poor miscibility of two components leads to a combined vapor pressures that do not follow the Raoult's law causing a lower boiling point for the mixture when compared to the individual components. In this case, students observed that the boiling of the mixture water-BITC occurred at near $100{ }^{\circ} \mathrm{C}$ (BITC, b.p. $242-243^{\circ} \mathrm{C}$ ) so it could be used to reinforce numerous concepts, such as vapor-liquid equilibrium, Raoult's law and azeotropic distillation. The use of Soxhlet extractor evidenced for the students the possible presence of more components since the extracts assumed a light yellow color.

By analyzing the ${ }^{1} \mathrm{H}$ NMR spectra (Figure 1) it was noted that the hydrodistillation method provided a selective strategy to extract BITC from papaya seeds. The signals corresponding to the BITC are in accordance with the literature. ${ }^{31}$ The quantitative analysis of the organic extracts (in duplicate) by HPLC revealed a mean value of $91.2 \%$ within $3 \mathrm{~h}$ of distillation (See the Supplementary Material). However, the extracts obtained from the continuous extraction (Soxhlet), revealed the predominance of triglycerides (see the Supplementary Material) as observed by the analysis of the aliphatic region in the ${ }^{1} \mathrm{H}$ NMR spectrum (range of $4.3-0.9 \mathrm{ppm}$ Figure 1). Indeed, the chromatographic quantifications obtained by Soxhlet indicated low recovery of BITC (15.9\% in $n$-pentane and $10.3 \%$ in $n$-hexane). The students could determine with success that while Soxhlet led to the extraction of almost all constituents present in the seeds, hydrodistillation only dragged the compound that have characteristics that allow co-distillation below of $100{ }^{\circ} \mathrm{C}$ (low solubility in water and relative vapor pressure).

In the second part of the organic lab, students were introduced to the qualitative tests with amines and BITC. They were encouraged to anticipate and comment the results. The observation of different reactivity patterns shed a light on the nucleophilicity concept as a key pedagogical component of this experiment. According to the visual progress of the reactions (white precipitate) along with TLC analysis, BITC was completely consumed when using benzylamine, butylamine, cyclohexylamine, isopropylamine, monoethanolamine
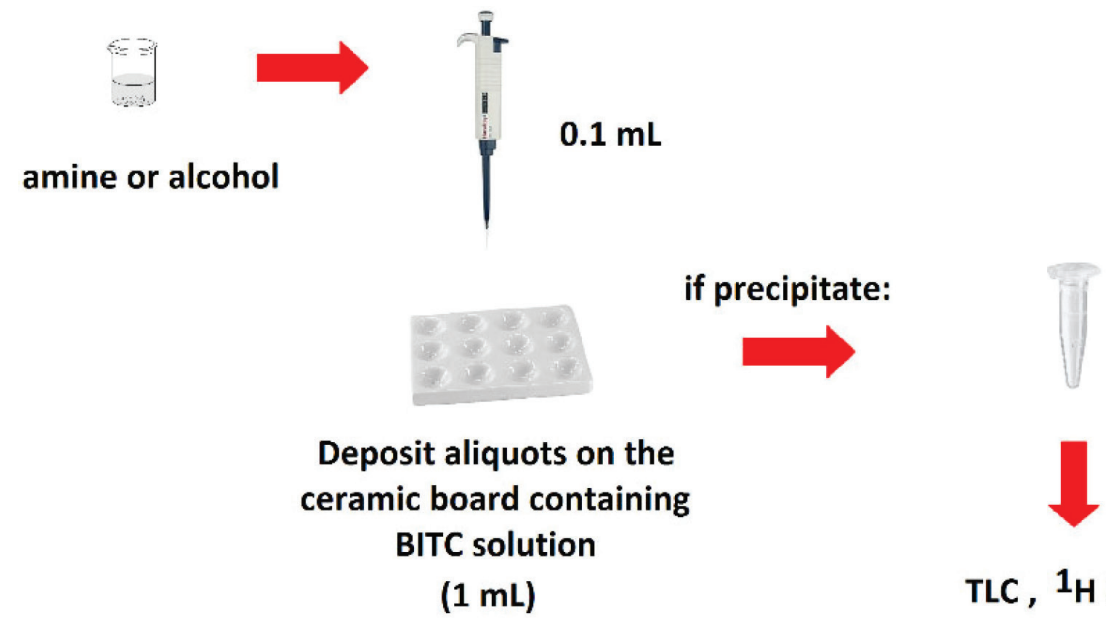

Scheme 6. Schematic for the nucleophilicity tests 


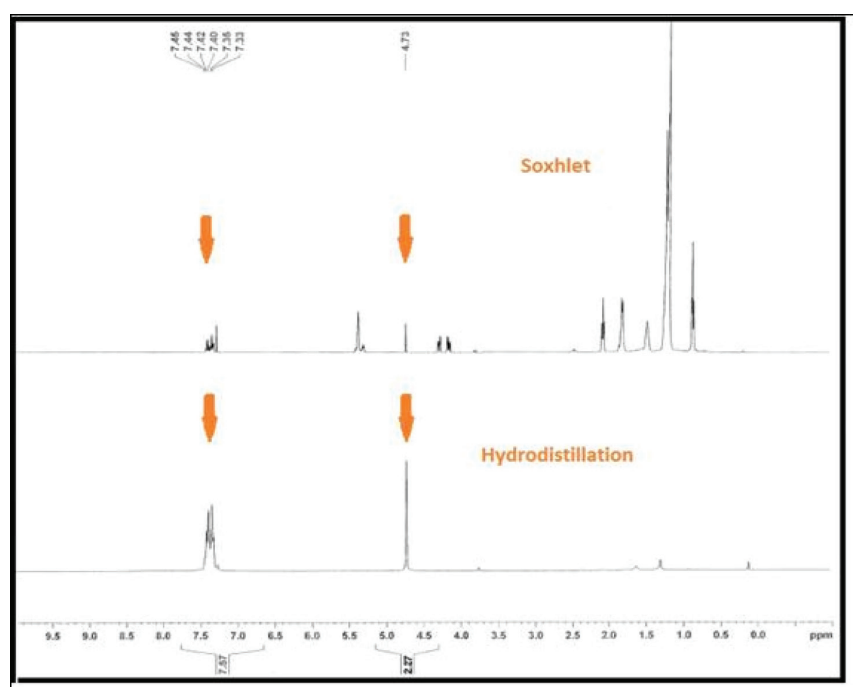

Figure 1. ${ }^{1} H$ NMR spectra comparing the extraction methods after 3 hours. The highlighted signals are related to the BITC chemical shifts

and morpholine as nucleophiles (Scheme 7 and Figure 2). The students confirmed which amines are nucleophilic and indicated whether the expected trend were correctly displayed. The spectra of the corresponding thioureas can be found in the Supplementary Material. Aniline was not able to react under this mild condition although the reaction appeared to be limited to the temperature, since precipitation occurred immediately after reflux. However, EWG-substituted anilines (e.g. 4-nitroaniline) and alcohols remained unreactive even under high temperature conditions thus evidencing a low nucleophilicity towards the isothiocyanate. To explain and engage students about some of the differences in results, the examination of what factors make a good nucleophile was the first goal. It should be noted that most students invoked the acid conjugated $\mathrm{pk}_{\mathrm{a}}$ 's to rationalize the results they observed. Since basicity (Table 1) is associated with thermodynamics while nucleophilicity is related to the kinetic behavior, the illustration of definitions along with how the terms can be used in different contexts was instructional. However, even though the results evidenced that the nucleophilicity of the different amines are in line with their conjugated acid pka values which are in the range of 10 (isopropylamine) to 8.5 (morpholine) $^{34}$ - nucleophilicities are not easily correlated with basicities. Mostly, predictions should be pointed out only if structural features in the immediate vicinity of the nucleophilic atom are similar. Regarding the phenylamine (aniline), this point requires the understanding of the electronic effects because the presence of electron-withdrawing groups can decrease the electron density on the reaction site. Indeed, concerning the expected result involving benzyl alcohol, the comparison with benzyl amine is illustrative to stablish a parallelism about the atom tendency to form new covalent bonds by sharing their electron pairs. Thus, two factors contribute to the observed reactivity. Indeed, we believe that drawing analogies with the Pearson's SHAB (Soft Hard Acid Base) approach greatly broadens the subject perspective having in mind the qualitative concept. Just as with $\mathrm{pk}_{\mathrm{a}}$ and $\mathrm{pk}_{\mathrm{b}}$ scales for Brønsted acids and bases, we hope that the building of nucleophilicity scales based upon relative reactivities in common organic reactions can stimulate comprehensive studies of analogous systems. ${ }^{35}$ Thus, these simple examples allow for an introductory discussion of the many important aspects related to physical organic chemistry and are desirable in the predictions of mechanistic studies of more complex reactions.

This organic experiment can be performed over a two-week period in order to improve critical thinking about the efficient valorization and transformation of a waste biomass-based material ${ }^{36,37}$ as well as to shed light on the nucleophilic reactivities. Depending on the curriculum, students can already have skills on the full characterization of organic compounds. In fact, the project would be best suited for those programs that introduce spectroscopy early in the organic chemistry sequence. In this case, students were encouraged to identify the worth spectral changes in the ${ }^{1} \mathrm{H}$ NMR spectra of products (See Supplementary Material) when comparing the signals from the starting materials.

Additionally, since the organic laboratory represents an important part of the foundation courses due to some necessary research skills, ${ }^{38}$ this alternative experiment can contribute to address the laboratory curriculum for a project-based approach. This strategy can provide flexibility in the implementation of the procedure and stimulate skills development envisaging an organic synthesis course. After the experiments, student comprehension was evaluated by a lab report and postlab exercises, which demonstrated their positive feedback concerning the concepts previously discussed. Specifically, they reported that both experiments were effective at helping them understand the physical principles involved and the ability of many nucleophiles to attack the isothiocyanate. More than $65 \%$ students were able to solve the problems without help. The result was compared to their performance in the prelab activity in which only $30 \%$ ones were able to obtain the total points. We found that the use of a common waste material for the experiments was effective for engaging each individual student. Interestingly, it motivated questions and additional research about the major components of some common listed raw materials since the proposal of novel biomass-derived materials was encouraged in the lab report conclusion. Finally, the building of a concept map for the experiment resulted in an enjoyable extra activity.

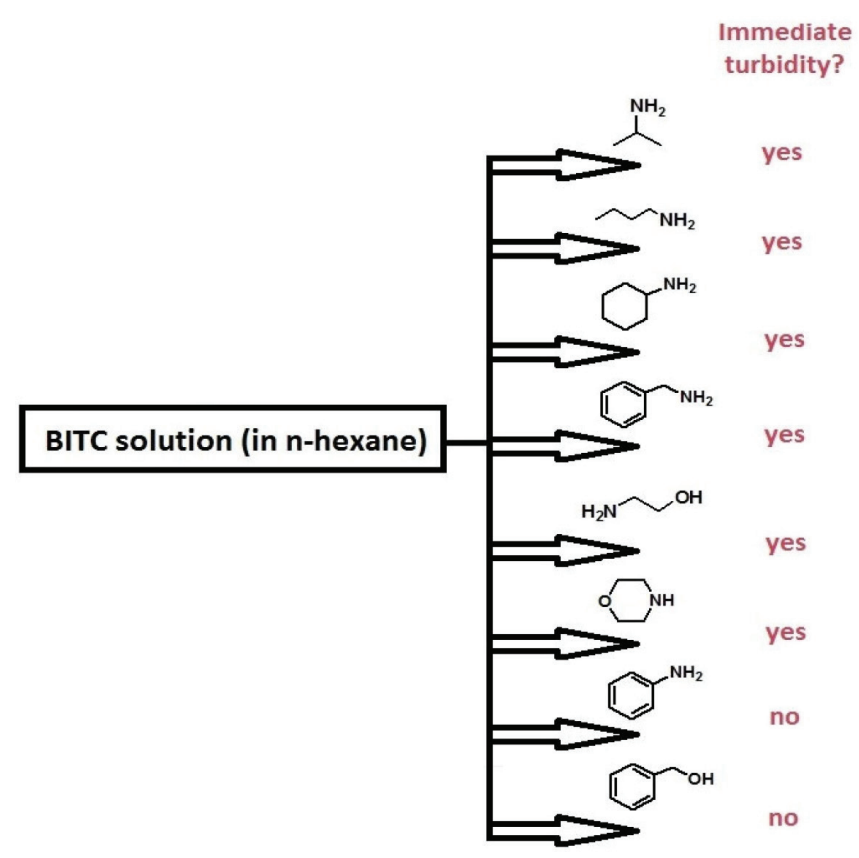

Scheme 7. Reactivity of different nucleophiles (amines and alcohols) towards BITC at room temperature (Part of the chart developed by the students in the form of concept map)

\section{CONCLUSION}

Given the rapidly evolving online and virtual instruction, the necessity for significant hands-on experiments in laboratory is required. We recognize that positive educational experiences for 
Table 1. Comparison between amine/alcohol (conjugated acids) $\mathrm{pk}_{\mathrm{a}}$ 's and nucleophilicity towards BITC ${ }^{(1)}$

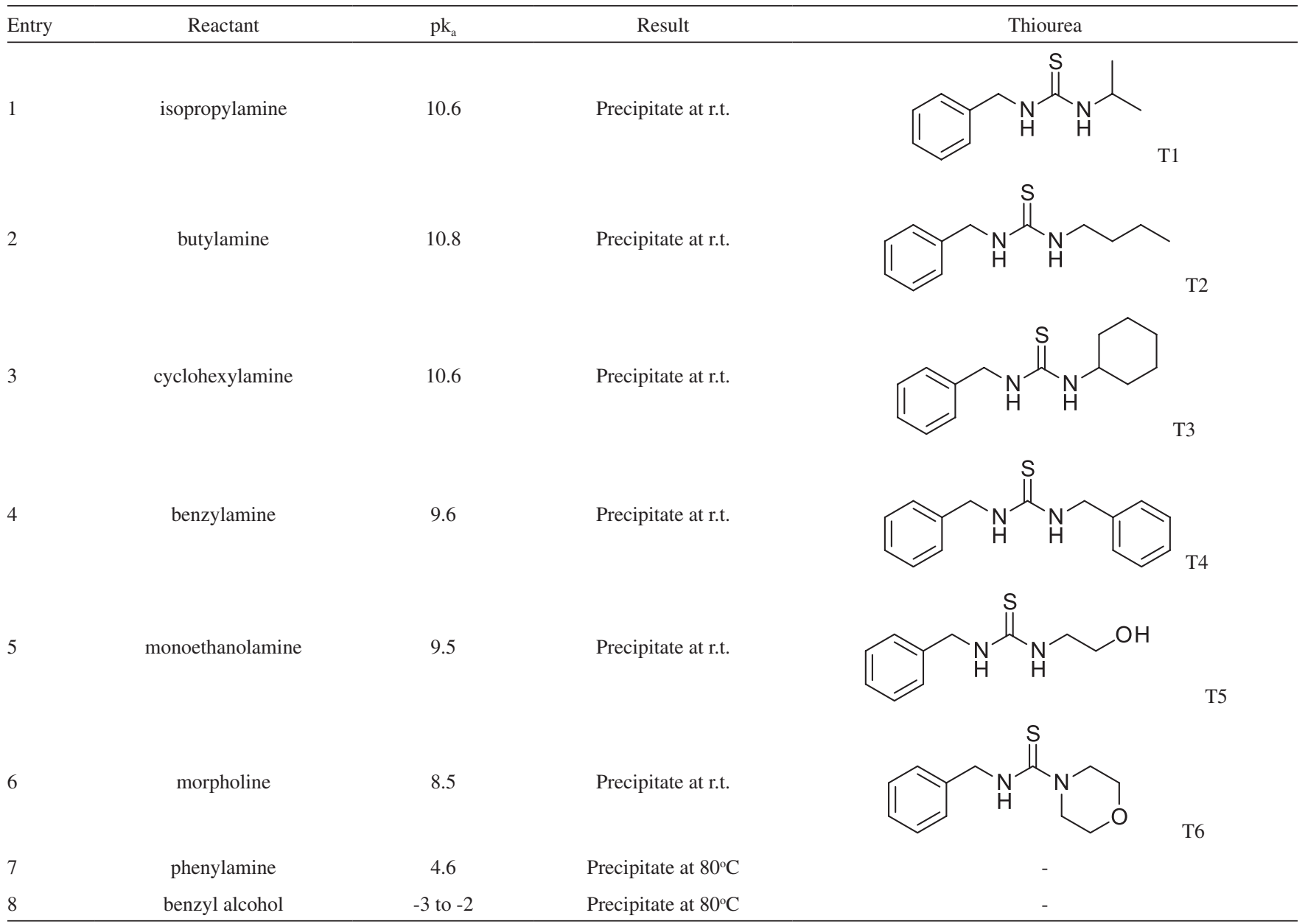

${ }^{(1)}$ The reaction progress was monitored by TLC. ${ }^{(2)}$ The corresponding thiourea was formed after about 30 seconds under reflux $\left(65^{\circ} \mathrm{C}\right) .{ }^{(3)}$ No precipitation was observed even after some minutes under reflux.

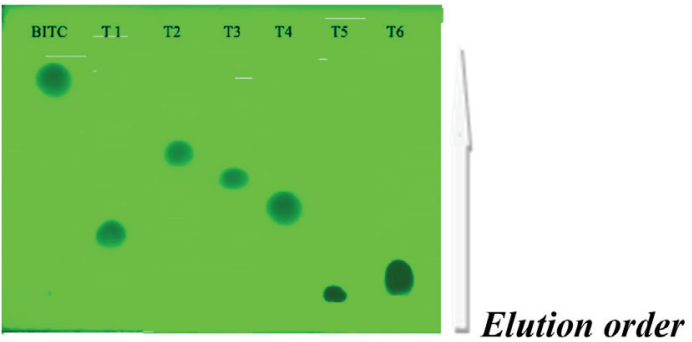

Figure 2. Image of the thin-layer chromatography run (20\% ethyl acetate in hexane, $\lambda=254 \mathrm{~nm}$ ) of thioureas (T1-T6, see Table 1) instantly prepared at room temperature with BITC extracted from papaya seeds

the students are fundamental to shed light on implementations for foundation courses. In general, organic laboratory experiments do not place emphasis on effective research experiences and students are not challenged to plan and discuss results along with think of how they can make their synthetic route more environmentally friendly. Herein, a biomass-based approach involving a research-oriented organic chemistry laboratory is presented. Since the nucleophilicity concept is intrinsic to the understanding of most organic reactions, this proposal for more advanced students provided an interesting activity to revisit the concept in light of sustainable chemical reactions: the use waste material from a renewable source, minimal energy and instantly visual reaction progress at mild conditions. Student comprehension was assessed through prelab and postlab activities, which revealed that they realized the importance of a project-based experience to build their knowledge about some specific topics. We suggest implementing this course in a second half of a more advanced organic lab or in a full course to go in depth on related topics such as natural products isolation /quantification, spectroscopic methods and benign synthesis by using bioplatform intermediates.

\section{SUPPLEMENTARY MATERIAL}

The following material is free of charge at http://quimicanova. sbq.org.br, in the PDF format: Laboratory procedure for students (Materials and methods); Spectral data and ${ }^{1} \mathrm{H}$ NMR spectra of thioureas T1-T6; In-class questions.

\section{ACKNOWLEDGEMENTS}

Authors acknowledge CNPq, FAPERJ by the financial support. In addition, this study was financed in part by the Coordenação de Aperfeiçoamento de Pessoal de Nível Superior - Brasil (CAPES) - Finance Code 001. We kindly acknowledge G.T.M. Filho for the supply of fresh papaya seeds.

\section{REFERENCES}

1. McCoy, A. B.; Darbeau, R. W.; J. Chem. Educ. 2013, 90, 398.

2. Larive, C. K.; McCoy, A. B.; Chem. Eng. News 2012, 90, 29. 
3. Wenzel, T. J.; McCoy, A. B.; Landis, C. R.; J. Chem. Educ. 2015, 92, 965.

4. Ragauskas, A. J.; Williams, C. K.; Davison, B. H.; Britovsek, G.; Cairney, J.; Eckert, A.; Frederick Jr., W. J.; Hallet, J. P.; Leak, D. J.; Liotta, C. H.; Mielenz, J. R.; Murphy, R.; Templer, R.; Tschaplinski, T.; Science 2006, 311, 484.

5. Corma, A.; Iborra, S.; Velty, A.; Chem. Rev. 2007, 107, 2411.

6. Besson, M.; Gallezot, P.; Pinel, C.; Chem. Rev. 2014, 114, 1827.

7. Alonso, D. M.; Wettstein; S. G.; Dumesic, J. A.; Chem. Soc. Rev. 2012, 41, 8075.

8. Hayes, D. J.; Catal. Today 2009, 145, 138.

9. Andraos, J.; Dicks, A. P.; Chem. Educ. Res. Pract. 2012, 13, 69.

10. Han, Z.; Park, A.; Su, W. W.; RSC Adv. 2018, 8, 27963.

11. Williams D. J.; Pun S.; Chaliha M; Scheelings, P.; O'Hare, T.; J. Food Compos. Anal. 2013, 29, 82.

12. Rossetto, M. R. M.; do Nascimento, J. R. O.; Purgatto, E.; Fabi, J. P.; Lajolo, F. M.; Cordenunsi, B. R.; J. Agric. Food Chem. 2008, 56, 9592.

13. Fahey, J. W.; Zalcmann, A. T.; Talalay, P.; Phytochemistry 2001, $56,5$.

14. Ettlinger, M. G.; Hodgkins, J. E.; J. Org. Chem. 1956, 21, 204.

15. Hanschen, F. S.; Klopsch, R.; Oliviero, T.; Schreiner, M.; Verkerk, R.; Dekker, M.; Sci. Reports (2017), DOI: 10.1038/srep40807.

16. Palmieri, S.; Leoni, O.; Iori, R.; Anal. Biochem. 1982, 123, 320.

17. Kermanshai, R.; McCarry, B. E.; Rosenfeld, J.; Summers, P. S.; Weretilnyk, E. A.; Sorger, G. J.; Phytochemistry 2001, 57, 427.

18. Soundararajan, P.; Kim, J. S.; Molecules 2018, 23, 2983.

19. Kumar, N. S.; PS, S. D.; J. Pharmacogn. Phytochem. 2017, 6, 424.

20. Senra, J. D.; Viana, G. M.; Malta, L. F. B.; Simas, A. B. C.; Aguiar, L. C. S.; ChemCatChem 2016, 8, 192.

21. Costa, M. V.; Aguiar, L. C. S.; Malta, L. F. B.; Viana, G. M.; Costa, B. B. S.; Tetrahedron Lett. 2016, 57, 1585.

22. Viana, G. M.; Aguiar, L. C. S.; Ferrão, J. A.; Simas, A. B. C.; Vasconcelos, M. G.; Tetrahedron Lett. 2013, 54, 936.
23. Shakeel, A.; Altaf, A. A.; Qureshi, A. M.; Badshah, A.; Journal of Drug Design and Medicinal Chemistry 2016, 2, 10.

24. Gale, P. A.; Busschaert, N.; Haynes, C. J.; Karagiannidis, L. E.; Kirby, I. L.; Chem. Soc. Rev. 2014, 43, 205.

25. Wenzel, M.; Hiscock, J. R.; Gale, P. A.; Chem. Soc. Rev. 2012, 41, 480.

26. Li, A. F.; Wang, J. H.; Wang, F.; Jiang, Y. B.; Chem. Soc. Rev. 2010, 39, 3729.

27. Steed, J. W.; Chem. Soc. Rev. 2010, 39, 3686.

28. Ghanei-Motlagha, M.; Fayazib, M.; Taherd, M. A.; Jalalinejad, A.; Chem. Eng. J. 2016, 290, 53.

29. Navarro, R.; Perrino, M. P.; García, C.; Elvira, C.; Gallardo, A.; Reinecke, H.; Polymers 2016, 8, 152.

30. Gale, P. A.; Pérez-Tomás, R.; Quesada, R.; Acc. Chem. Res. 2013, 46, 2801.

31. Aguiar, L. C. S.; Viana, G. M.; Romualdo, M. V. S.; Costa, M. V.; Bonato, B. S.; Lett. Org. Chem. 2011, 8, 540.

32. As a matter of fact, $N$-substituted thioureas have been prepared by using hazardous and toxic protocols (e.g. reaction with thiophosgene): See Sharma, S.; Synthesis 1978, 11, 803.

33. Even though all experiments were performed in adequate fume hoods, it was possible to detect some BITC odor. If the experiment is increased in scale we recommend the use of a mask.

34. Perrin, D. D.; Dempsey, B.; Serjeant, E. P.; $p K_{a}$ Prediction for Organic Acids and Bases, $1^{\text {st }}$ ed., Springer: Netherlands, 1981.

35. Ibne-Rasa, K. M.; J. Chem. Educ. 1967, 44, 89.

36. McKenzie, L. C.; Huffman, L. M.; Hutchison, J. E.; J. Chem. Educ. 2009, 86, 488.

37. Parajó, J. C.; Domínguez, H.; Santos, V.; Alonso, J. L.; Garrote, G.; J. Chem. Educ. 2008, 85, 972.

38. Weaver, M. G.; Samoshin, A. V.; Lewis, R. B.; Gainer, M. J.; J. Chem. Educ. 2016, 93, 847. 